\section{Effect of live oud music on physiological and psychological parameters in patients undergoing cardiac surgery}

Merna Luis ${ }^{\mathbf{1}}$, Ramy Doss¹ Basel Zayed $^{\mathbf{2}}$ Magdi Yacoub ${ }^{1}$

${ }^{1}$ Aswan Heart Centre, Aswan, Egypt ${ }^{2}$ Music and Art therapist, Ellenhorn, Massachusetts, USA

*Email: mernaluis2014@gmail.com

https://doi.org/

10.21542/gcsp.2019.17

Received: 11 July 2019

Accepted: 18 August 2019 (C) 2019 The Author(s), licensee Magdi Yacoub Institute. This is an open access article distributed under the terms of the Creative Commons Attribution license CC BY-4.0, which permits unrestricted use, distribution and reproduction in any medium, provided the original work is properly cited.

\section{ABSTRACT}

Background. Music therapy has emerged as a promising evidence-based adjuvant method of intervention. This study aims to assess the effect of live oud music on physiological and psychological parameters in patients undergoing cardiac surgery, pre- and post-operatively. Methods. Twelve patients undergoing cardiac operations were randomly allocated into either intervention group or control group, six patients in each group. Patients in the intervention group listened to 20 minutes of improvised and personally customized live oud music before and after surgery while patients in the control group heard the normal hospital sounds. While anxiety scores were assessed preoperatively, vital signs and pain scores were assessed postoperatively together with serum levels of cortisol, which was used as a surrogate marker of the stress response.

Results. In the intervention group, pain scores and respiratory rates showed statistically significant reduction after listening to music (P values of 0.043 and 0.034 respectively). Additionally, heart rates, anxiety scores and serum cortisol levels showed borderline significant reduction in patients who listened to music with $\mathrm{P}$ values, $0.063,0.066$ and 0.068 respectively. These changes were not found in the control group.

Conclusions. This preliminary study suggests a role of live oud music therapy in decreasing stress response of the patients undergoing cardiac surgery, in addition to its positive effects on pain perception and anxiety scores.
Cite this article as: Luis M, Doss R, Zayed B, Yacoub M. Effect of live oud music on physiological and psychological parameters in patients undergoing cardiac surgery, Global Cardiology Science and Practice 2019:17 https://doi.org/10.21542/gcsp.2019.17 


\section{INTRODUCTION}

Over the past few decades, music therapy has emerged as promising evidence-based adjuvant treatment addressing various organic and psychiatric illnesses ${ }^{1-5}$.

Major surgical procedures are known to be associated with considerable pain, anxiety and hemodynamic disturbances. Thus, the use of music therapy as an adjuvant therapy to alleviate perioperative anxiety and alter pain perception has been of a particular interest.

In this study, we aimed to explore the effect of live music intervention on various hemodynamic parameters, anxiety and pain perception scores as well as serum cortisol level as a surrogate markers of stress response in patients undergoing cardiac surgery.

While various studies have discussed the efficacy of passive music therapy using recorded music as an adjuvant therapeutic intervention ${ }^{6}$, much less is known about the efficacy of live music interventions in patients undergoing surgery.

To the best of our knowledge, this study represents the first randomized trial to examine effects of music therapy on Egyptian patients, using Arabic and Middle Eastern music.

\section{METHODS}

The study took place at Aswan Heart Centre, Aswan, Egypt, between November 2018 and February 2019, using a single-centre, prospective, open- label randomized controlled trial design. According to the inclusion criteria, twelve adult patients were eligible to participate in the study. They were 18 years old or above, undergoing either elective septal myectomy, valve replacement, or coronary artery bypass graft operations. Patients were excluded if they were unconscious, sedated, haemodynamically unstable or on inotropic support. They were also excluded in case of co-morbidities that might interfere with the study results, such as advanced kidney or liver diseases.

After consenting, the patients were randomly allocated into either experimental or control group. Patients in the experimental group received sessions of 20-30 minutes of live relaxing oud music performed by a trained oud player. Melodies, duration, volume, tempos and scales were selected based on the individual explicit preference of every patient in addition to the oud player's insight. Structure of the music therapy sessions was planned ahead with a credentialed music therapist.

The first session was performed two hours before surgery. Anxiety scores were assessed using a certified Arabic translation of Hamilton Anxiety assessment scale ${ }^{7}$ before and after the music intervention for the experimental group. Postoperatively, after patients were extubated and weaned of vasopressors, music sessions were resumed on the 1st and 2nd post-operative days. Systolic and diastolic blood pressure, heart rate, respiratory rate, oxygen saturation and pain scores (using the Visual Analogue Scale ${ }^{8}$ ) were recorded before and after music 24 and 48 hours postoperatively. Additionally, serum cortisol levels were measured using electrochemiluminescence immunoassay (ECLIA) within 30 minutes before and after music on the 1st day.

For the control group, music therapy sessions were replaced with periods of rest, in which the patients heard the typical hospital sounds. Same measurements were recorded. Data were collected by personnel blinded to group assignments.

Statistical analysis was performed using SPSS version 18.0 (SPSS Inc., Chicago, Illinois). Due to the non-normal distribution and small sample size, data were expressed as median and interquartile range. Repeated measures were compared using Wilcoxon Signed Ranks Test. P values less than 0.05 were considered statistically significant. 
Table 1 Results for experimental and control groups.

\begin{tabular}{|c|c|c|c|}
\hline & Pre- intervention ${ }^{*}$ & Post- intervention & $P$ value \\
\hline \multicolumn{4}{|c|}{ HR (bpm) 1st day } \\
\hline experimental & $85(73.50-89.00)$ & $82(72.50-86.50)$ & 0.063 \\
\hline control & $96(92.00-102.00)$ & $95(90.00-104.50)$ & 1 \\
\hline \multicolumn{4}{|c|}{ HR (bpm) 2nd day } \\
\hline experimental & $80(67.50-90.00)$ & $79(66.50-79.00)$ & 0.059 \\
\hline control & $92(83.50-102.00)$ & $95(86.00-98.50)$ & 0.892 \\
\hline \multicolumn{4}{|c|}{ RR (bpm) 1st day } \\
\hline experimental & $30(26.50-32.00)$ & $26(21.00-28.50)$ & 0.043 \\
\hline control & $26(25.00-38.50)$ & $32(24.50-33.50)$ & 0.893 \\
\hline \multicolumn{4}{|c|}{ Anxiety $(0-56)$} \\
\hline experimental & $14(10.25-21.25)$ & $7(6.00-7.25)$ & 0.066 \\
\hline control & $8(2.75-12.00)$ & $8(2.75-12.00)$ & 1 \\
\hline \multicolumn{4}{|c|}{ Pain (0-10) 1st day } \\
\hline experimental & $7(6.00-7.50)$ & $5(3.50-5.50)$ & 0.034 \\
\hline control & $7(3.00-9.00)$ & $7(3.00-9.00)$ & 1 \\
\hline \multicolumn{4}{|c|}{ Pain $(0-10)$ 2nd day } \\
\hline experimental & $5(3.00-6.00)$ & $3(1.00-4.50)$ & 0.039 \\
\hline control & $5(1.50-7.50)$ & $5(1.50-7.50)$ & 1 \\
\hline \multicolumn{4}{|c|}{ S- Cortisol (nmol/L) } \\
\hline experimental & $1170(399.50-1552.00)$ & $945(287.50-1524.00)$ & 0.068 \\
\hline control & $592(243.20-1410.00)$ & $880(392.40-1376.00)$ & 0.515 \\
\hline
\end{tabular}

Notes.

*Values expressed as median (inter-quartile range IQR).

${ }^{*} \mathrm{P}<0.05$ is considered statistically significant.

${ }^{*} \mathrm{HR}$, heart rate, $\mathrm{RR}$, respiratory rate.

\section{ETHICAL CONSIDERATIONS}

The study was approved by the local ethical committee of Aswan Heart Centre. All participants gave informed written consents after being explicitly provided with information about the study.

\section{RESULTS}

Twelve patients were included in this preliminary analysis, six men and six women of median age 48 years. Six patients were in the experimental group and six in the control group. They were comparable regarding their age, sex and type of surgery.

In the intervention group, statistically significant reduction in respiratory rates was observed in the first postoperative day $(\mathrm{P}<0.043)$ as well as pain scores in the first $(\mathrm{P}$ $<0.034)$ and second days ( $P$ <0.039). Additionally, borderline significant reductions in heart rates in first $(P<0.063)$ and second $(P<0.059)$ days, anxiety scores $(P<0.066)$ and serum cortisol levels ( $\mathrm{P}<0.068$ ) (Table 1 ). In the control group, no statistically significant differences were found in any measured parameter. In both groups, no significant differences were demonstrated regarding systolic or diastolic blood pressure or oxygen saturation levels. 


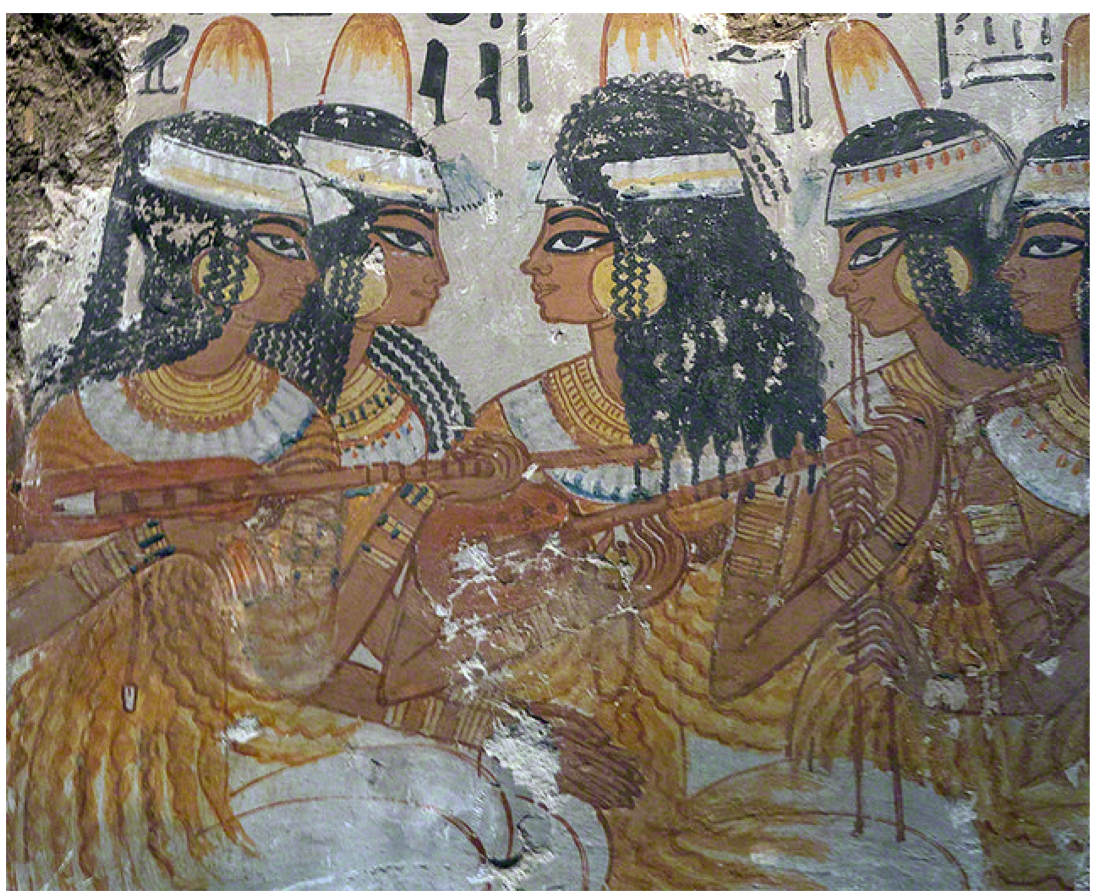

Figure 1. Egyptian lute or oud players. Fresco found in Thebes, from the tomb of Nebamun, a nobleman in the 18th Dynasty of Ancient Egypt (c. 1350 BC).

\section{DISCUSSION}

In Ancient Egypt, harp was used for healing purposes to address many illnesses of mind and body9,10 (Figure 1). It is mentioned that Imhotep, one of the greatest physicians in Ancient Egypt ${ }^{11,12}$ used music therapy and constructed a sanatorium for this purpose ${ }^{10}$. Use of music therapy, especially for pain relief, was also evident hundreds of years ago during the Islamic Era ${ }^{13}$.

Reseach in this field has been growing over the past few decades, with a view of integrating music therapy into the conventional medical practice.

The results of this preliminary study emphasize some positive effects of live music therapy on various physiological and psychological parameters. Clinically, music resulted in statistically significant reduction in heart rate and respiratory rate. This is consistent with the findings of previous studies which presented evidence of decreased heart and respiratory rates ${ }^{14-19}$.

However, in contrast to these studies, no statistically significant changes in blood pressure were found in our study. With regard to the psychological parameters, music therapy significantly decreased preoperative anxiety and postoperative pain scores. These effects were also proved in many previous studies ${ }^{14,15,20-30}$.

In some systematic reviews including all randomized clinical trials that compared music intervention with standard care to standard care only, researchers concluded that music intervention might have a beneficial effect on preoperative anxiety ${ }^{14,15,20-24}$, especially when patients are involved in the music selection process ${ }^{15}$.

Many other RCTs have been done to assess the effect of music intervention on different kinds of pain in children and adults, most of them concluded that music can be used as a beneficial adjuvant modality for reducing pain perception 25-30 (Figure 2).

As cortisol is a known component of the endocrine stress response to surgeries ${ }^{31}$, serum cortisol level was used in this study as a surrogate biochemical marker to stress 


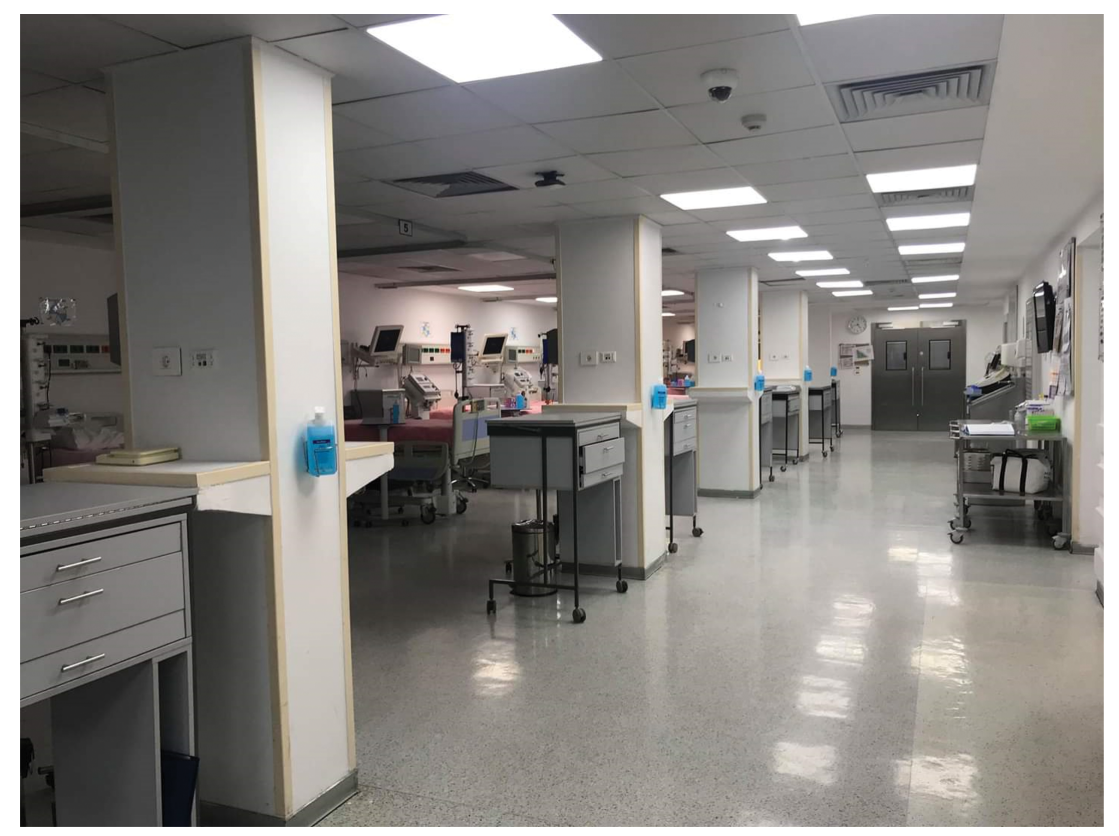

Figure 2. ICU unit at Aswan Heart Centre.

response and was found to decline significantly in response to live oud music. Similarly, Leardi et al found a statistically significant reduction of serum cortisol level in patients who had undergone day surgeries, after listening to music ${ }^{32}$. Regarding stress response to cardiac surgery, a statistically significant difference of serum cortisol levels between the music group and control group was found ${ }^{33}$.

While the exact mechanism of the positive central effects of music remains unknown, some studies have attributed this to positive distraction ${ }^{34}$, cognitive role of pain control ${ }^{35}$, and increased levels of beta-endorphins ${ }^{36}$ resulting in positive emotional responses and mood changes ${ }^{37-40}$.

Functional neuroimaging studies have allowed better understanding of the unique response of brain to music. Studies have highlighted modulation of metabolic activity of brain structures involved in emotional regulation in response to music, giving rise to autonomic and endocrine responses $39,41-43$. Increased dopamine activity in the mesolimbic system occurs in response to anticipation and listening to the preferable kind of music associated with peak emotional response ${ }^{44}$.

In this context, we selected a lute-type musical instrument deeply rooted in Arabian culture, the 'oud', given its soothing effect and familiarity to Arab and Egyptian patients (Figure 3). Carl Jung talked about the concept of collective subconscious and how society makes use of the inherited creative material for meaning making and soothing. The collective unconscious is "the part of the psyche that retains and transmits the common psychological inheritance of mankind. These symbols are so ancient and unfamiliar to modern man that he cannot directly understand or assimilate them" 45 . Perhaps this is the reason why it is soothing to use an authentic instrument. Moreover, live music involves having the therapist with the patient which brings empathy together with the concept of "here and now" to the relationship46.

Furthermore, we categorized the music therapy sessions into two major sections; firstly, patients' favorite songs were played upon their request, and secondly, improvisation using a unique, culturally- based approach called the 'Maqam' system. Maqam is a scale system in the Arabic and Middle Eastern musical heritage. The wide 


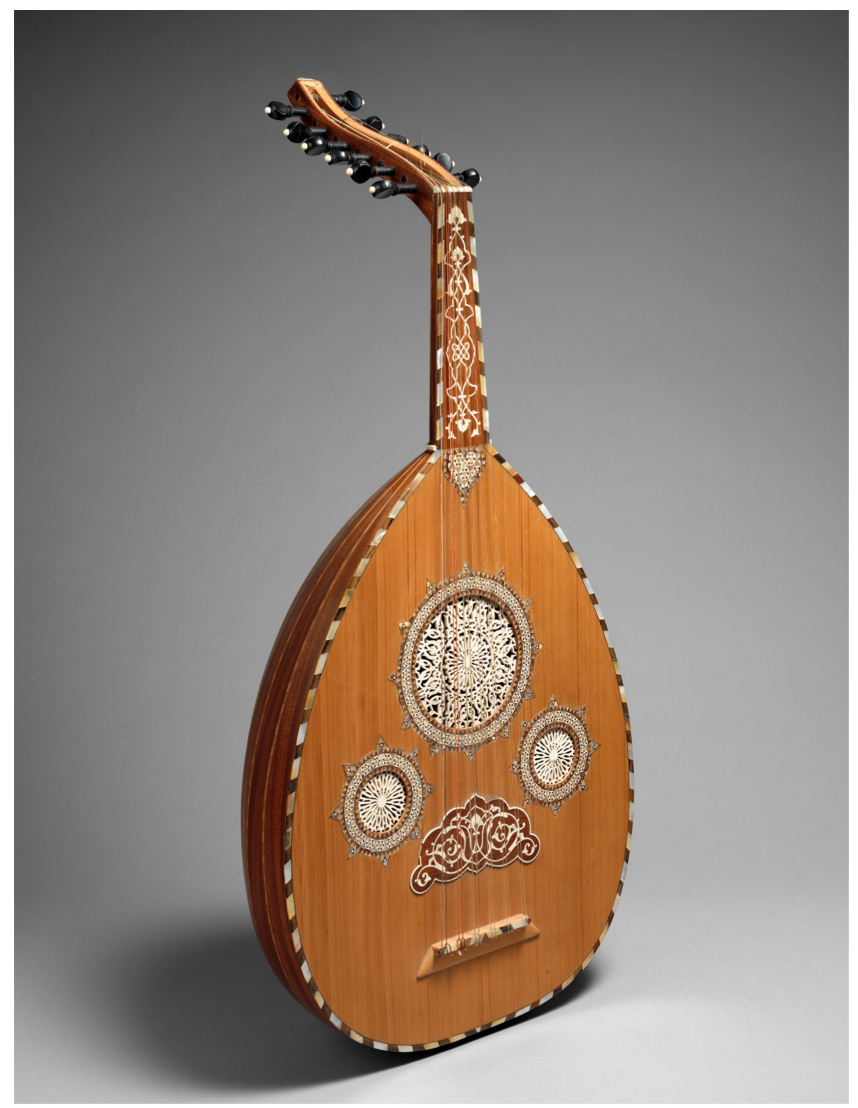

Figure 3. A typically traditional Egyptian oud.

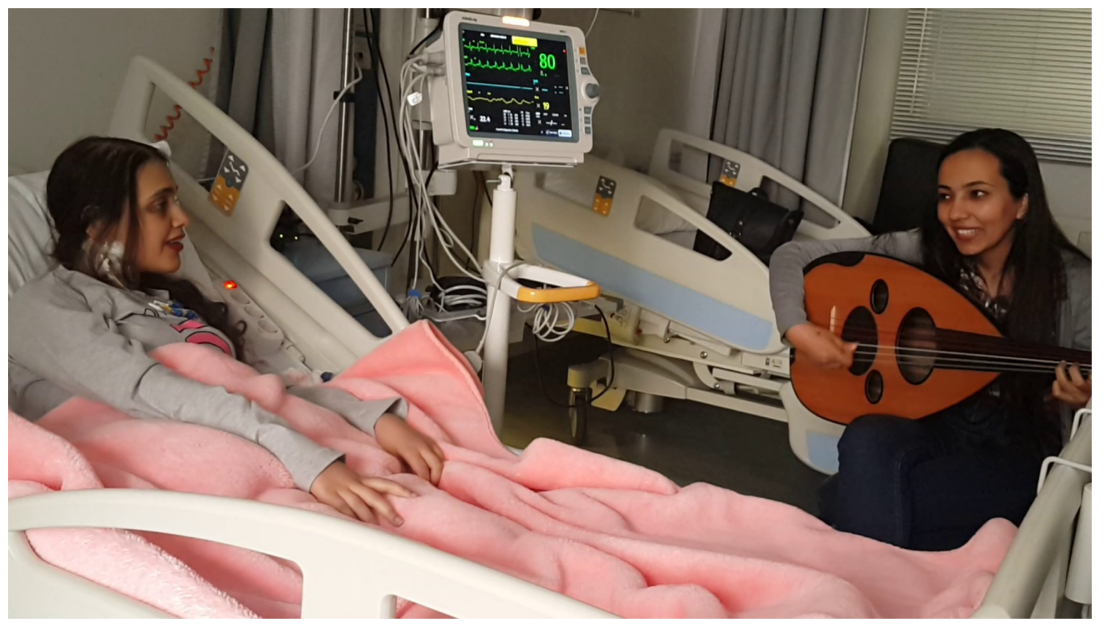

Figure 4. A live oud therapy session taking place at the Aswan Heart Centre.

range of tones produced in Maqam is significantly important to underscore. The specific healing texture brought from the variety of tones produces an abundance of scale colors which allows the composer to improvise to express a deeper and more emotionally and socially connected sound (Figure 4).

We felt it was necessary to develop a therapeutic alliance which is used to give patients a sense of choice and help them feel responsible and safe. This is in line with 
what Carl Rogers states about the therapist-patient relationship: "The relationship is one which provides the client with the opportunity of making responsible choices" 46 .

This method enabled us to achieve an individualized approach facilitating the active involvement and engagement of patients in the music making process. During each session, patients chose between four different scales, performed by the musician, without being informed of the name, purpose or nature of each scale. Then improvisation within the chosen maqam was performed which might helped the patients express specific subjective emotions.

Interestingly, it was observed that the most commonly chosen scales were Bayati and Kurd while Hijaz was the second popular choice. Moreover, the popular songs requested by the patients lied within the same scales. This observation might reflect the nature of the music genre preferred to Arab and Egyptian native listeners which might help reach a peak response and a maximum benefit. 44

\section{STUDY LIMITATIONS}

The study is limited by the small number of patients which might cause some false negative results, lack of follow up for sustained clinical benefits and lack of clinical translation of the neuro-hormonal changes. Finally, problems related to questionnairebased studies, such as response bias, were faced.

Permission for the reproduction of the patient's identifying features in Figure 4 was freely given and obtained by the authors.

\section{CONCLUSION}

The results of this preliminary study suggest a role for live oud music therapy in decreasing stress response of the patients undergoing cardiac surgery, showing statistical significant reduction in respiratory rate, heart rate, pain and anxiety scores as well as cortisol levels. It might also emphasize the importance of improvised, patientcentered live music intervention. However, further studies are needed to compare efficacy of live versus passive music interventions, and to provide a complete picture of Arab and Egyptian patients' therapeutic musical preferences.

\section{REFERENCES}

[1] Guetin S, Portet F, Picot MC, Pommié C, Messaoudi M, Djabelkir L, Olsen AL, Cano MM, Lecourt E, Touchon J. Effect of music therapy on anxiety and depression in patients with Alzheimer's type dementia: randomised, controlled study. Dementia and Geriatric Cognitive Disorders. 2009;28(1):36-46.

[2] Maratos A, Gold C, Wang X, Crawford M. Music therapy for depression. Cochrane Database of Systematic Reviews. 2008(1).

[3] Erkkilä J, Punkanen M, Fachner J, Ala-Ruona E, Pöntiö I, Tervaniemi M, Vanhala M, Gold C. Individual music therapy for depression: randomised controlled trial. The British Journal of Psychiatry. 2011;199(2):132-9.

[4] Bradt J, Magee WL, Dileo C, Wheeler BL, McGilloway E. Music therapy for acquired brain injury. Cochrane Database of Systematic Reviews. 2010;7(2).

[5] Okamoto H, Stracke H, Stoll W, Pantev C. Listening to tailor-made notched music reduces tinnitus loudness and tinnitus-related auditory cortex activity. Proceedings of the National Academy of Sciences. 2010;107(3):1207-10.

[6] Nilsson U. The anxiety-and pain-reducing effects of music interventions: a systematic review. AORN Journal. 2008;87(4):780-807.

[7] Hamilton M. The assessment of anxiety states by rating. Br J Med Psychol. 1959;32:50-55.

[8] Scott J, Huskisson EC. Graphic representation of pain. Pain. 1976;2(2):175-84.

[9] Horden P (ed.) Music as medicine: The history of music therapy since antiquity. Routledge:2017.

[10] Available from: https://www.tokenrock.com/sound_healing/sounds_of_the_ancients/.

[11] Musso CG. Imhotep: the dean among the ancient Egyptian physicians. An example of a complete physician. Humane Medicine Health Care. 2005;5:169. 
[12] Osler W. Evolution of modern medicine. DevCom; 1921.

[13] Sina Al. Al-Qanun fi al-tibb.1025.

[14] Wiwatwongwana D, Vichitvejpaisal P, Thaikruea L, Klaphajone J, Tantong A, Wiwatwongwana A. The effect of music with and without binaural beat audio on operative anxiety in patients undergoing cataract surgery: a randomized controlled trial. Eye. 2016;30(11):1407.

[15] Bradt J, Dileo C, Potvin N. Music for stress and anxiety reduction in coronary heart disease patients. Cochrane Database of Systematic Reviews. 2013(12).

[16] Byers JF, Smyth KA. Effect of a music intervention on noise annoyance, heart rate, and blood pressure in cardiac surgery patients. American Journal of Critical Care. 1997;6(3):183-91.

[17] White JM. Effects of relaxing music on cardiac autonomic balance and anxiety after acute myocardial infarction. American Journal of Critical Care. 1999;8(4):220.

[18] Hatem TP, Lira PI, Mattos SS. The therapeutic effects of music in children following cardiac surgery. Jornal de Pediatria. 2006;82(3):186-92.

[19] Camara JG, Ruszkowski JM, Worak SR. The effect of live classical piano music on the vital signs of patients undergoing ophthalmic surgery. The Medscape Journal of Medicine. 2008;10(6):149.

[20] Nilsson U. The anxiety-and pain-reducing effects of music interventions: a systematic review. AORN Journal. 2008;87(4):780-807.

[21] Klassen JA, Liang Y, Tjosvold L, Klassen TP, Hartling L. Music for pain and anxiety in children undergoing medical procedures: a systematic review of randomized controlled trials. Ambulatory Pediatrics. 2008;8(2):117-28.

[22] Wang SM, Kulkarni L, Dolev J, Kain ZN. Music and preoperative anxiety: a randomized, controlled study. Anesthesia \& Analgesia. 2002;94(6):1489-94.

[23] Nilsson U, Unosson M, Rawal N. Stress reduction and analgesia in patients exposed to calming music postoperatively: a randomized controlled trial. European Journal of Anaesthesiology. 2005;22(2):96-102.

[24] Bradt J, Dileo C, Shim M. Music interventions for preoperative anxiety. Cochrane Database of Systematic Reviews. 2013(6).

[25] Ayoub CM, Rizk LB, Yaacoub Cl, Gaal D, Kain ZN. Music and ambient operating room noise in patients undergoing spinal anesthesia. Anesthesia \& Analgesia. 2005;100(5):1316-9.

[26] Gallagher LM, Lagman R, Rybicki L. Outcomes of music therapy interventions on symptom management in palliative medicine patients. American Journal of Hospice and Palliative Medicine ${ }^{\circledR}$. 2018;35(2):250-7.

[27] Nilsson U, Rawal N, Unosson M. A comparison of intra-operative or postoperative exposure to music-a controlled trial of the effects on postoperative pain. Anaesthesia. 2003;58(7):699-703.

[28] Gutgsell KJ, Schluchter M, Margevicius S, DeGolia PA, McLaughlin B, Harris M, Mecklenburg J, Wiencek C. Music therapy reduces pain in palliative care patients: a randomized controlled trial. Journal of Pain and Symptom Management. 2013;45(5):822-31.

[29] Li XM, Yan H, Zhou KN, Dang SN, Wang DL, Zhang YP. Effects of music therapy on pain among female breast cancer patients after radical mastectomy: results from a randomized controlled trial. Breast Cancer Research and Treatment. 2011;128(2):411-9.

[30] Mitchell LA, MacDonald RA. An experimental investigation of the effects of preferred and relaxing music listening on pain perception. Journal of Music Therapy. 2006;43(4):295-316.

[31] Desborough JP. The stress response to trauma and surgery. British Journal of Anaesthesia. 2000;85(1):109-17.

[32] Leardi S, Pietroletti R, Angeloni G, Necozione S, Ranalletta G, Del Gusto B. Randomized clinical trial examining the effect of music therapy in stress response to day surgery. British Journal of Surgery: Incorporating European Journal of Surgery and Swiss Surgery. 2007;94(8):943-7.

[33] Nilsson U. The effect of music intervention in stress response to cardiac surgery in a randomized clinical trial. Heart \& Lung: The Journal of Acute and Critical Care. 2009;38(3):201-7.

[34] Shepley MM. The role of positive distraction in neonatal intensive care unit settings. Journal of Perinatology. 2006;26(S3):S34.

[35] Bushnell MC, Čeko M, Low LA. Cognitive and emotional control of pain and its disruption in chronic pain. Nature Reviews Neuroscience. 2013;14(7):502.

[36] Qiu J, Jiang YF, Li F, Tong QH, Rong H, Cheng R. Effect of combined music and touch intervention on pain response and $\beta$-endorphin and cortisol concentrations in late preterm infants. BMC Pediatrics. 2017;17(1):38.

[37] Villemure C, Bushnell CM. Cognitive modulation of pain: how do attention and emotion influence pain processing? Pain. 2002;95(3):195-9.

[38] Roy M, Peretz I, Rainville P. Emotional valence contributes to music-induced analgesia. Pain. 2008;134(1-2):140-7.

[39] Blood A), Zatorre RJ. Intensely pleasurable responses to music correlate with activity in brain regions implicated in reward and emotion. Proceedings of the National Academy of Sciences. 2001;98(20):11818-23.

[40] Koelsch S. Brain correlates of music-evoked emotions. Nature Reviews Neuroscience. 2014;15(3):170.

[41] Alcaro A, Huber R, Panksepp J. Behavioral functions of the mesolimbic dopaminergic system: an affective neuroethological perspective. Brain Research Reviews. 2007;56(2):283-321. 
[42] Blood AJ, Zatorre RJ, Bermudez P, Evans AC. Emotional responses to pleasant and unpleasant music correlate with activity in paralimbic brain regions. Nature Neuroscience. 1999;2(4):382.

[43] Menon V, Levitin DJ. The rewards of music listening: response and physiological connectivity of the mesolimbic system. Neuroimage. 2005;28(1):175-84.

[44] Salimpoor VN, Benovoy M, Larcher K, Dagher A, Zatorre RJ. Anatomically distinct dopamine release during anticipation and experience of peak emotion to music. Nature Neuroscience. 2011;14(2):257.

[45] Jung CG. The collected works of CG Jung. Vol. 9: The archetypes and the collective unconscious. Trans. RFC Hull, Princeton NJ: Princeton University Press; 1969.

[46] Rogers CR. Client-centered therapy: Its current practice, implications, and theory. Boston: Houghton Mifflin; 1965. 